Proceedings of the 2011 Winter Simulation Conference

S. Jain, R.R. Creasey, J. Himmelspach, K.P. White, and M. Fu, eds.

\title{
COMBINING SUSTAINABILITY CRITERIA WITH DISCRETE EVENT SIMULATION
}

\author{
Andi H. Widok \\ Volker Wohlgemuth \\ HTW Berlin, University of Applied Sciences \\ Industrial Environmental Informatics Unit \\ Wilhelminenhofstrasse 75A \\ D-12459 Berlin, GERMANY
}

\author{
Bernd Page \\ University of Hamburg \\ Department of Informatics \\ Vogt-Kölln-Strasse 30 \\ D-22527 Hamburg, GERMANY
}

\begin{abstract}
This paper attempts to highlight shortcomings in the concept of sustainability and ways to make the concept more workable by presenting the development of an Environmental Management Information System (EMIS) as a combination of discrete event simulation and ecological material flow analysis for production processes. The motivation behind the focus on simulation techniques on one hand and on production processes on the other, is the understanding that the current metabolic rates of today's economies are beginning to affect the life-sustaining services of the earth. Dematerialization and resource efficiency are mandatory concepts in the coming decades, hence the production processes; simulation techniques are needed as existing systems cannot be easily changed to be experimented with. There is however a lack of simulation systems addressing sustainability as a whole. This paper intends to show ways on how to connect supposedly opposite factors and thus getting closer to the so called immeasurable: sustainability.
\end{abstract}

\section{INTRODUCTION AND MOTIVATION}

Sustainability has been one of the fastest-growing areas of activity in research in recent decades (Gasparatos, El-Haram and Horner 2007). Despite this positive development, the technological assessment and ITsupported management of sustainability criteria is just at its very beginning; especially simulation systems do not yet pay tribute to the complex interdependencies of economic, ecological and social values. That is as the concept and its capacity still remain elusive even now, 24 years after the Brundtland Commission report that brought them into prominence (Gasparatos, El-Haram and Horner 2007).

This following Section will address the underlying problems of current developments and therefore describe the motivation behind the development of the EMIS that will be presented in Section 3.

Without intending to debate how anthropogenic the climate change and its consequences are, many of its effects have been empirically proven and they will consequently change the socio-economic requirements on earth within coming decades (IPCC 2007; Rottke 2009; Benz 2009). Effects such as the extinction of species (Butchart et al. 2004; Butchart et al. 2007), deforestation (Corbera, Estrada and Brown 2010), changes in ice distribution (Mallory et al. 2010), droughts and increasing incidence of forest fires and other consequences of human influence on the environment, as the development of greenhouse gas emissions, especially CO2-emissions (IPPC 2007) and the overfishing of the seas (FAO 2007) will have a huge impact on the quality of life and the equity in distribution in the coming century. In that regard the World Resources Forum (WRF) stated:

"Globalizing the traditional model of economic growth is leading to rapidly increasing consumption of limited natural resources, followed by ecological disruption. Current economic and environmental policies have not been able to stop these trends. (...) Rising global consumption of raw materials (...) is be- 
ginning to affect the life-sustaining services of the earth, which are not replaceable by technical means. (...) Today, the fundamental flaw in human activities is the enormous consumption of natural resources per unit output of value or service. (...) The environmental safety threshold has already been surpassed, as is evident from various "developments" (...). And yet, only some 20 per cent of humankind enjoy the full benefits of the mainstream economic model, while all people - in particular the poor - have begun to suffer the consequences of its flaws" (WRF 2008).

Despite phases with little or no economic growth, it is unlikely that the ecosystem will experience periods of natural regeneration in the coming decades, rather the opposite in fact. If one looks at current metabolic rates in the world (OECD 2008), one finds that they are still rising (Hilty and Ruddy 2010) (Figure 1). The WRF estimates that global resource extraction will exceed 80 billion tons in 2020 . This would mean that mankind would have doubled the annual rate of global resource extraction within only 40 years (1980-2020) (WRF 2008).

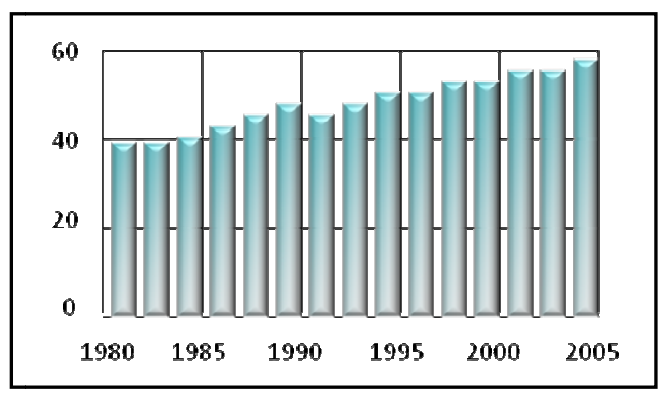

Figure 1: Global Resource Extraction, (SERI 2008)

From a system-thinking point of view, it is evident that the behavior and interaction of systemelements are currently beginning to endanger the stability of the system itself. In this respect, one can recognize various escalating curves, that are consequently not reduced to an environmental perspective. To clarify this point, one can consider the catching-up processes involving emerging industries and countries such as China and India; morally there is no argument why these economies should not be "allowed" to prosper and grow as the more industrialized countries once did, while at the same time there is a "physical impossibility" (Hilty and Ruddy 2010) of extending the present consumption patterns of the industrialized countries to all parts of the world. The already existing inequality of distribution is not likely to diminish, which will ultimately lead to new social problems.

When bearing in mind the ecological part of the problem, one could argue that the encompassing system is becoming unstable or out of balance, due to excessive pressure on several ends. Balance being the keyword in the last sentence, as finding the right balance is basically the common denominator for the social problem as well. What could be considered as excessive or unjust pressure on the ecological side could be translated to unequal or unjust distribution on the social side with analogue dramatic results/effects.

Given the growing metabolic rates of the emerging countries one must be realistic and see that of course people will try to reach a similar high state of wealth and prosperity. In a capital orientated world this implies to own a certain quantity of commodities and thus consumption, which then again reinforces production. Due to the impossibility mentioned, the only way to preserve the current or a currentcomparable standard of living throughout industrialized countries, emerging countries and all others, would be to find ways to reduce resource usage to an extent that would allow the same high level of production using only a fraction of the raw resources. In order to sustain our economy without completely revising our standard of living, the only way is the dematerialization of our economies and greater resource efficiency. Without much higher efficiency justice in distribution will remain an empty promise (The social perspective will be discussed in more in detail in Section 4). 
The needed processes of transformation would make investment imperative. The financial sector however is currently experiencing problems of its own. The financial crisis of 2007/08, the very recent developments surrounding the Euro (Greece) and also the Dollar and the government/budget deficit in the United States ought to demonstrate that a capital orientated society does not necessarily result in a surplus of money. Also it shows how interdependent the global market already is today. The consequences of the crisis can be observed on the large scale already referred to but also at the level of small and medium sized enterprises (SME) that are failing to obtain necessary loans from banks.

Basically it comes down to a similar problem of distribution as that which applies to raw resources. If we consider a company as a minimal representation of an economy, we understand that with a purely economic orientation it will not lead to sustainable growth (see Section 4). A strong social commitment or intensive environmental management, however, will not have any positive effects if the company structure cannot bear the load they place on it either. Thus it is imperative that these three measures of sustainability are combined by means of balanced efforts leading to a synergistic increase in value (Stahlmann 2008; Schmidt-Bleek 2008; von Pappenheim 2009; Colantonio 2009).

This balance in efforts is what sustainability has been trying to define from the very outset. Throughout sustainability theory, from Meadows (1972), Lynam and Herdt (1989) and Pezzey (1992) (who already listed 27 different definitions for sustainability), Pretty (1995) to Bell and Morse (2008), there has been a broad understanding that processes must preserve/protect/balance various objectives, while sometimes also shrinking processes can be considered sustainable.

\section{DEFINING SUSTAINABILITY CRITERIA FOR USE IN SIMULATION}

In the introduction, we stated that sustainability addresses the problems of distribution, it therefore follows the ideals of intra- and intergenerational justice and is a conclusion of the realization that human actions have consequences, if not for themselves then for other people with a shift in space or time. Consequently, we understand sustainability as perception and acceptance of this responsibility and therefore as a need to act.

\subsection{The Measurement of Sustainability}

Environmental and economic issues dominated the sustainability debate at its beginning whilst it is only in the late 1990s that social issues were taken into account within the agenda (Colantonio 2009). Currently there is an active interest in sustainability indicators/composite indices (Esty et al. 2005; Bell and Morse 2008). These indices contain indicators that capture sustainability issues relevant to the context of the specific assessment exercise (UN 2001; Hjorth and Bagheri 2006). The indicators are subsequently being aggregated to a single composite index or left disaggregated according to the intentions of the analysts. Aggregation choices are usually a tradeoff between loss of information when aggregated and fuzziness when disaggregated (Gasparatos, El-Haram and Horner 2007).

In view of the fact already explained, that it is not possible to have an equal distribution of wealth, resources and products in the world within a short period of time (where short can be 50 years or more) and simultaneously to preserve the ecosystem, it follows that the ideals of intra- and intergenerational justice cannot be satisfied at this point in time (Hilty and Ruddy 2010). Therefore, the concept of sustainability must be regarded as the means to achieve intra- and intergenerational justice and is consequently normative.

\subsection{A Capital Oriented Definition of Sustainability}

To ensure that there is a clear understanding of the following, we will define sustainability under a capital-based approach (see also McElroy, Jorna and van Engelen 2007): 
Widok, Wohlgemuth and Page

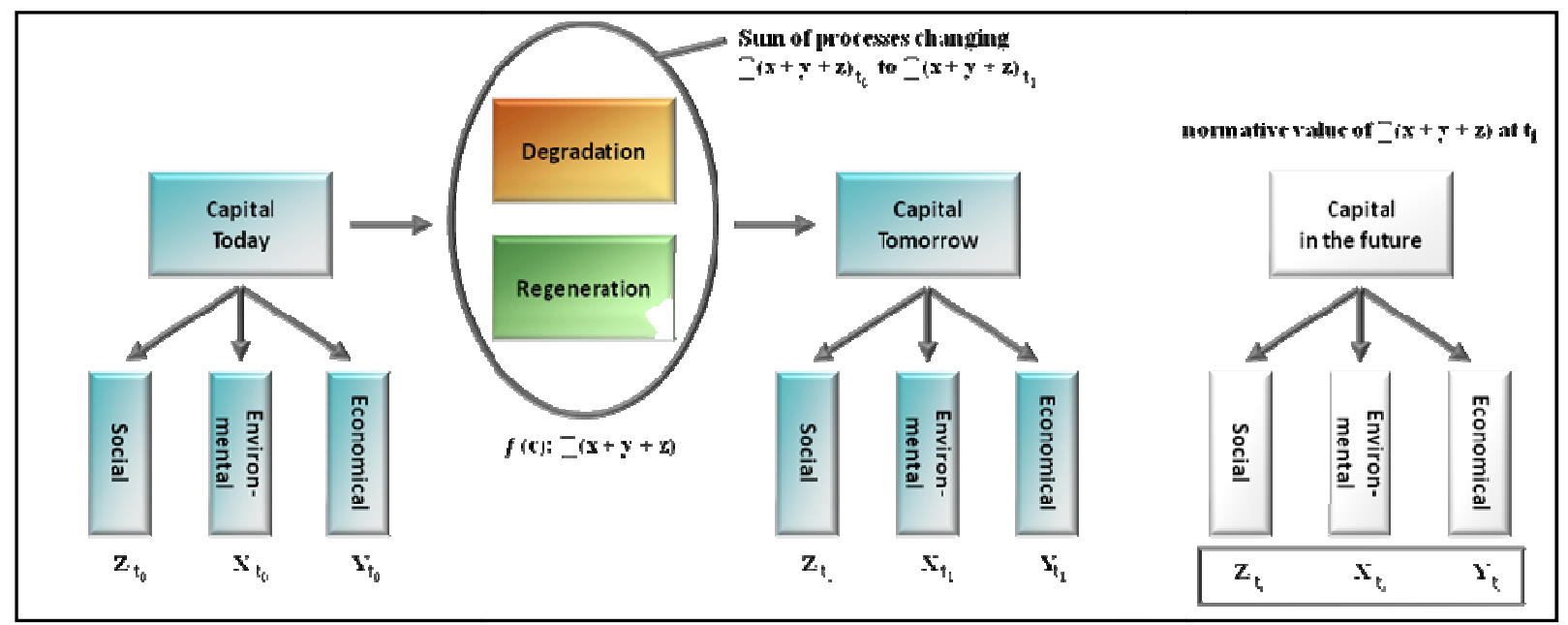

Figure 2: Capital Approach - Sustainability

Referring to Figure 2 we define sustainability mainly as the agglomeration of actions/campaigns/processes that have a positive effect on the regeneration of social, environmental and/or economical capital on the one hand, and/or reduce the degradation of this capital on the other. That is, as the normative value of that capital is supposedly higher or equal to the initial amount of that capital, otherwise an inversion of signs would result. A third option being the allowance of the use of a different source, or not having to use the capital in question at all any longer. An example of this would be the usage of new processes allowing the substitution of different materials insofar as the old material would no longer be needed for the process and the new material would be less of a drain on overall capital.

The main problem with this definition lies in the specification of what social/economic/environmental capital is. While no one will argue that it exists, one can argue about the concrete indicators and the attributed values behind them or, more specifically, about the value-correlations between them. This is also what makes it so difficult to define a sustainable process. While a process may be very ecologically sustainable when measuring the amount of material used, it may also be very expensive and therefore, drain economic capital or vice versa. Also the influence of a process may, with a reduced perception on this one process only, be very much ignorable, but when a whole line of business is using the same method it can become a problem. In that regard a top down regulation must be in place, while the reporting must be bottom-up. The exact proportions on when which capital should have a higher coefficient remains unsolved as already mentioned in the introduction. The value behind the "three pillars" of sustainability (environmental, social, economical) would be composed out of a set of indicators depending on the task at hand (see Section 2.1), but reflecting the top down regulation in place.

Another problem is the definition of the normative value(s), but in order to qualify a process to be sustainable one does not have to know the exact value, a relative approach or binary approach - see also McElroy, Jorna and van Engelen (2007) - can suffice. We argue that environmental indicators and indicators related to Corporate Social Responsibility (CSR-related) have been greatly undervalued in recent decades (von Pappenheim 2009; Dubielzig 2009). While we do not believe that every single process in a company can, or even should be broken down into a value, we believe it to be possible, to do this with many more processes than it is the case at present and especially with more environmental and social processes. In order to get closer to sustainability as a whole, it is thus imperative to find more and more indicators, that really reflect the consequences a production or service process is having not only on the company but on the environment and the people as well. The often argued thesis, that the three pillars of sustainability should be weighted equally cannot be reflected scientifically when for economic questions there are many more valid indicators, while for environmental the indicators are sometimes very interde- 
pendent and the social ones are partly not even acknowledged or agreed upon. While we realize that this definition of sustainability indicators is one of the most critical parts of sustainability assessment, the overall definition in conjunction with intended usage in simulation experiments allows many different approaches and indicator compositions to be tested in experiments and then validated when assessing the sustainability-enhancing potential of intended measures in practice. Thus simulation can be a way to assess the sustainability of new processes and give allow for new information on how the different perspectives may be connected.

\subsection{Simulation Criteria for Production Optimization}

Simulation can be used to show the possible effects of alternative conditions and courses of action. It has many fields of application, for example when the real system cannot be engaged, because it may not be accessible, or it is being designed but not yet built (Sokolowski and Banks 2009). In that regard simulations are perfect tools when it comes to experiment with uncertain outcomes, which may be harming or contra-productive as well as the planning of new production lines or amendments to existing ones.

The main target of resource efficiency (Section 1) deduced the used simulation focus and had been laid on usage in production. The improvement of production is directly connected to the in- and output relations and consists of the attempt to get more returns while investing lesser resources (Wöhe and Döring 2008). This process is also called optimization and it is target-oriented (e.g. optimizing the costs, quality, efficiency or effectiveness). Optimizations can also be achieved using an operations research approach (Domschke et al. 2008) or analytical methods. The operations research approach however becomes problematic once one has to deal with many variables. That is precisely when simulations are more worthwhile. The simulation of production addresses a variety of different indicators, the most common measures of system performance being the following (Banks et al. 2005):

- Throughput under average and peak loads;

- System cycle time (how long it take to produce one part);

- Utilization of resource, labor, and machines;

- Bottlenecks and choke points;

- Queuing at work locations;

- Queuing and delays caused by material-handling devices and systems;

- Work in progress (WIP) storage needs;

- Staffing requirements;

- Effectiveness of scheduling systems;

- Effectiveness of control systems.

These indicators can be considered as the most general value set of today's production optimization, they however do not incorporate environmental or social indicators and hence an optimization of the production using these key-indicators would go only in one direction, leading to a higher output and higher effectiveness. Even though a higher production could have positive effects on social capital, these are far from guaranteed. In the coming chapter we'll illustrate the integration of the environmental perspective in a same model used for simulation runs. In Section 4 we will then propose our current vision on how to integrate the social perspective and thus paying tribute to all three pillars of sustainability.

\section{DEVELOPMENT OF THE MATERIAL FLOW SIMULATOR MILAN}

\subsection{Combining discrete event simulation components with material flow analysis}

During several different research projects the Informatics Department of the University of Hamburg has been experimenting with modeling and simulation as suitable methods for EMIS. The techniques of modeling and simulation have been established as an important instrument for the analysis and planning of complex systems in many domains (Page and Kreutzer 2005). 
The deduction from investigations at the beginning of the century was the proposal to use simulation techniques for supporting the application of the Material Flow Network method (Figure 3) (Wohlgemuth, Bruns and Page 2001; Wohlgemuth 2005).

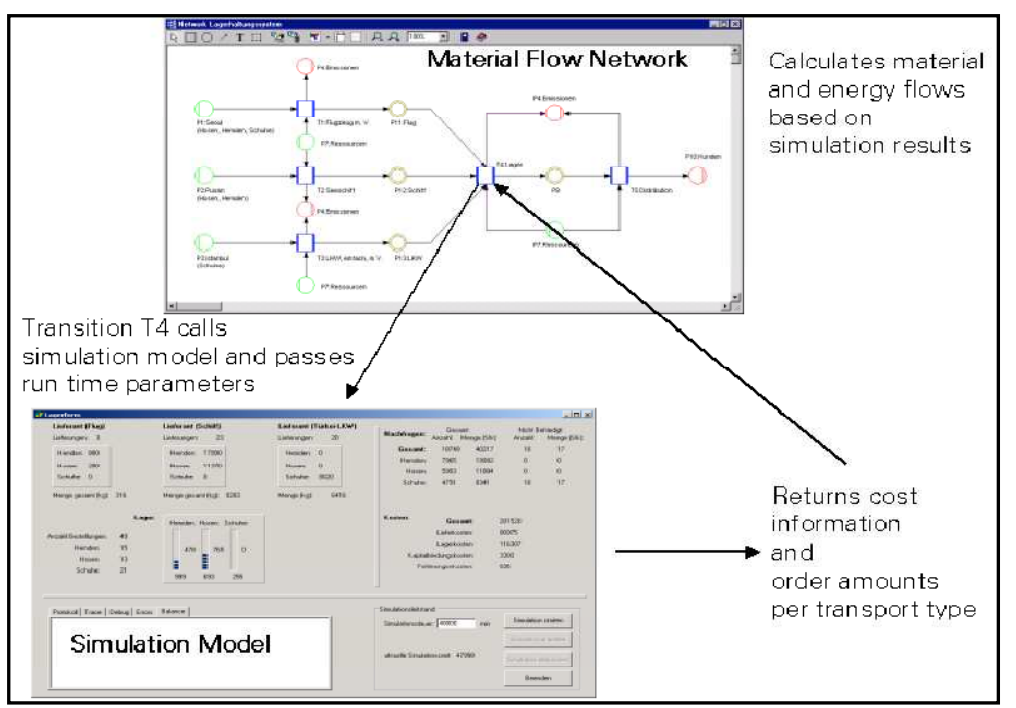

Figure 3: Linking discrete event simulation to Material Flow Networks (Wohlgemuth, Bruns, Page 2001)

Following that proposal, simulations can be used to calculate unknown environmental quantities. For example, it allows determining the necessary load of connected input flows considering complex systems (Joschko, Wohlgemuth and Page 2009).

In a sense, the material flow perspective is more general than the discrete event perspective (Wohlgemuth, et al. 2006) . Information is rarely linked to objects like products or process steps. Material Flow Networks, which were also developed at the University of Hamburg (Möller 2000), are based on the Petri-Net theory.

During one of the latest research projects, the prototype modeling- and simulation software named MILAN was developed (Wohlgemuth, Page, and Kreutzer 2006). On one hand, its discrete event simulation components allow an accurate analysis of typically economic aspects and industry related aspects, presented under point 2.3 , and on the other hand, its material flow analysis components did add for the first time an environmental perspective to the discrete event simulation model, i.e. a consideration of relevant material flows and transformations such as:

- consumption of commodities, resources and additives;

- energy demand;

- waste accumulation;

- Emission generation.

Discrete event simulations are a powerful method to represent production processes close to reality and to follow time intervals of different sizes from millisecond intervals up to several business years depending on the aspects under investigation. With the generation of pseudo-random numbers following given stochastic distributions, natural variations such as varying inter-mediate arrival times of production jobs can be represented.

In the Proceedings of the Winter Simulation Conference in 2009 we presented one of the first application of the Material Flow Simulator Milan, while it was first presented in 2006 (Wohlgemuth, Page, and Kreutzer 2006). Since then we intensified our work on different levels of the architecture and extensions of the simulation engine as elucidated in the next Section. 
Widok, Wohlgemuth and Page

\subsection{Ongoing Development}

MILAN was re-implemented in 2009 as the first implementation was realized using the Delphi version of DESMO-J, called DESMO-D, the framework and components in high level language Delphi and this realization seemed outdated and was not making use of the new capabilities of more powerful programming languages (Joschko, Wohlgemuth and Page 2009).

For MILAN it was necessary to provide libraries of simulation components (e.g. for production systems: machines, transporters, system boundaries) which enable the modeler to represent and simulate his system adequately and thus the new development of the material flow simulator MILAN was based on the open-source plugin framework EMPINIA (http://www.empinia.org).

EMPINIA, which was developed in the course of the EMPORER project, is designed for the development of complex domain-specific applications especially in the field of environmental management information systems (EMIS) (Wohlgemuth et al. 2008). It is a component-orientated extensible application framework based on Microsofts.NET technology with the purpose to support and simplify the development of complex software systems.

This implementation may lead to an easy development of user-specific components with low dependencies and an attachment to a modeling tool box for a certain application field, which is not possible with other simulation tools (Page et al. 2000; Page et al. 2005). These components can either be generally applicable or might be used for very specialized purpose. Specialized entities are developed for a whole production sector (e.g. semi-conductor sector with coater, stepper and dispatcher) (Wohlgemuth et al. 2004; Wohlgemuth et al. 2005) or they represent a production component of a certain company with its specific parameters. In contrast general components are highly abstracted and are applicable for many production systems (Jahr et al. 2009). The goal of this project was the development and implementation of such general entities for MILAN.

The general entities that were developed enable users to model and simulate a broad set of production systems. Because of their modularity and the plugin mechanisms of EMPINIA it is very easy to add more specialized entities to the production system's domain and to use them for a material flow simulation.

Following this step the production components were verified by performing a simulation study in a company that produces solar panels. The results and experiences of this validation were used to improve and enhance the components, the simulation infrastructure and MILAN as a simulation tool, itself.

The simulation capabilities of the MILAN software consist of the following elements:

- The simulation core consists of the central simulation service, interfaces and abstract base classes for models, experiments and model entities. These are used in each kind of simulation. The simulation service provides models and experiments in a way that other software parts can use them. The simulation core gives models and their entities access to the functionality of a domain model service. A domain model defines the domain of an EMPINIA-based application, its elements and their relations as well as rules that apply to this domain. MILAN consists of the domain 'simulation' with elements like 'model' and 'entity'. Among other important functionalities the domain service provides possibilities to persist its elements. That is the reason why this service is used in MILAN to save and load formerly created models.

- A bundle for discrete event simulation extends the simulation core with classes specific to the discrete event simulation approach. These classes are using an EMPINIA extension that enables the development of logical graphs in order to combine entities of a model to a network diagram. The basic generic experiment component is extended with an event list and a scheduler, which are used to simulate time in discrete steps.

- The simulation components have access to many stochastic distributions (e.g. Normal and Bernoulli). They are used to generate streams of random numbers, for example to schedule an event which follows a certain arrival probability. Additional to these existing distributions user-defined distributions can also be added via plugins. 
Besides the components which come with EMPINIA there are many plugins taken from an designed EMIS toolbox and were then combined with MILAN. These are shown in Figure 4. Furthermore we will shortly explain how these plugins are stacked together.

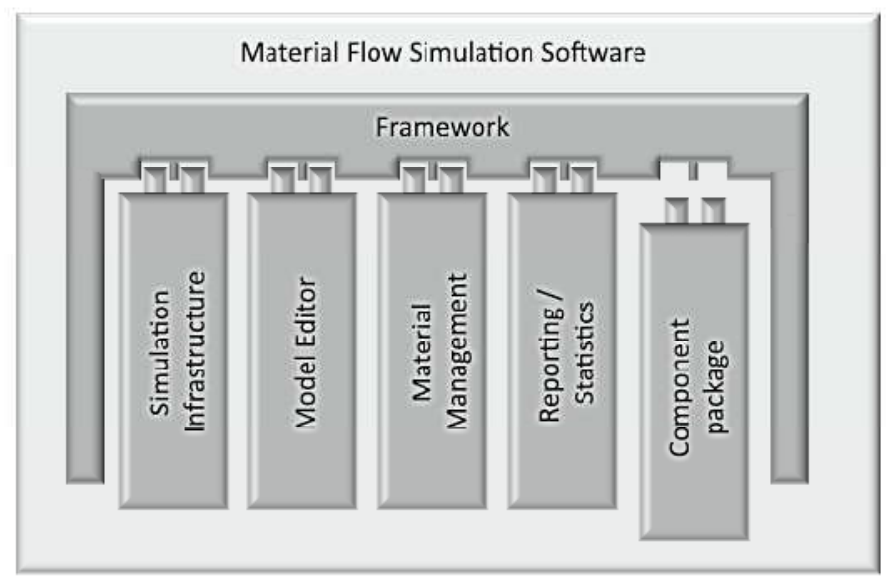

Figure 4: Material Flow Simulation Software and its framework (Jahr et al. 2009)

The common features of the MILAN software consist of the following elements:

- Graphical manipulation of building blocks lead to a faster development of a model. The graph editor can be used to create and manipulate models. The editor itself can work in different domains. Domain specific functionality and the graphical representation have to be defined by plugin developers enabling the editor to handle new domains and their components.

- Manipulating model parameter for the simulation and material flow perspective is done by means of property editors enabling a simple and consistent way of setting values for all types of properties. For the production system domain there are standard editors implemented. These allow the change of component specific parameters like setting distributions, accounting rules, queue lengths or capacities etc.

- No analysis can be done without results. These are shown in reports which can be designed with the help of the reporting system. The data for the reports is aggregated during simulation runs by a system of observers that listen to changes in the material accounting and simulation entities.

The development of new features and the testing of the full capacity of MILAN's functionality is ongoing. The Combination of economical and ecological indicators in one model has already been achieved. In the coming Section we'll outline visions on how MILAN might get even closer to a sustainability enhancing simulation system.

\section{THE VISION OF SIMULATING SUSTAINABILITY}

For companies, the main priority and thus the focus of interest must naturally be the financial side, otherwise the company could not survive under normal market conditions and thus neither produce. In an often cited interview the Nobel Prize Winner Milton Friedman said: "So the question is, do corporate executives, provided they stay within the law, have responsibilities in their business activities other than to make as much money for their stockholders as possible? And my answer to that is, no they do not." (February 1974) (from Dubielzig 2009). Even if one would tend to agree with Friedman, there are already numerous examples of when and how this statement would be economically disadvantageous, considering for example Nike and their incident with child labor in their supply chain (cf. Insight Investment 2003) or the case of Brent Spar (the sinking of an oil platform operated by Shell UK) (see Mantow 1995), or more recently British Petrol (BP) with an even more disastrous effect. These examples make obvious that the 
long term goal of profit maximization can only be achieved when at least parts of the social responsibility are acknowledged as well (Bakan 2005; Mintzberg 1983; Dubielzig 2009). In the case of Nike, the sales figures dropped after their incident, resulting in a stock loss of 20 per cent (Insight Investment 2003; Murray 2002; Leitschuh-Fecht and Bergius 2007, Dubielzig 2009), BP even suffered a stock loss of 50 per cent. This shows that the connection between social causes and economical consequences is very real.

The range of management approaches that look at social sustainability is relatively vast, so that one faces an unmanageable diversity of what are referred to as 'solutions'. Usually social aspects are considered under legal compliance. There are however not many software solutions that pick up on social aspects and where they do their usage is rather infrequent. This fact alone narrows down the search for universal applications, but also opens another perspective on the much more discussed "opposition" between the achievement of economical and ecological objectives (Colantonio 2009).

To make companies realize that they must aim not merely for financial stability, it is mandatory that corporate social responsibility (CSR) and environmental efforts come by a financial attribute and thus have an economic value too. The lack of these values, or rather their unspecific nature in the past, has led to many of today's undesirable developments, as profit is often solely attributed with financial growth while social, human, environmental profit is only of relevance when it comes to legal compliance (Colantonio 2009; von Pappenheim 2009).

In that regard current research at the HTW Berlin also tries to incorporate social indicators for the assessment of sustainable growth in production. Through the EMPINIA extension mechanism it is possible to define new resources, in this regard, human resources. These resources are then getting attributes, such as, for example, workload/contract information and references to the workstations, these references are basically the skills of the current employees. In order to pay tribute to the different abilities of the employees the workstations themselves are more or less in dependence of human resources to function properly and the human resources have a variety of criteria that, for example inhibits them to work 30 hour shifts. There is a whole framework of social criteria possible to be attributed to these new "resources", however research is still on its very beginning. The first focus of the introduction of social criteria will be health. Employees should not work longer then a certain amount of time, should take and have the possibility to take all their vacation and should not get in contact with any harming environmental emissions, noise, particular matter or other harming material. Even though that does not sound very revolutionizing it is the first step in addressing more complex interactions, such as financial equilibrium, daycare for children or other criteria.

We hope that in the future, after testing the introduction thoroughly we can implement more and more criteria and deduce and define new mathematical functions of correlation and interdependencies. That is as models will be validated and continuously extended with new indicator sets that are currently under development.

The introduction of these indicator sets is also planned to be on different levels, resulting in different reports rather than having non-validated criteria influence the simulation progress. The general idea is to have different reports over the same time period which could then be used to make assumptions over possible value correlations. These would then be used to experiment with new implemented functions derived from the indicators and then again resulting in a validation process. In cooperation with several producing enterprises we thus intend to gain new knowledge about measurable, applicable indicator sets for social sustainability criteria.

\section{CONCLUSION AND OUTLOOK}

In this paper we tried to give new input to the ongoing discussion on how to assess sustainability and more precisely the sustainability of producing companies. We tried to show in the introduction that no matter which pillar of sustainability is considered the negative influence, the loose ends, are likely to be a result of a system-imbalance. They are the underlying conditions for most of the problems we face today. We also tried to show that the change of human economies will become imperative and must be managed in a way that intends to address the issue of participation, which we consider to be one of the main prob- 
lems of the sustainability dilemma. People and companies, as system-elements will not intensify their positive influence unless the instability of the system is made obvious to them. The combination of different perspectives of sustainability in one model might contribute to this thesis and will therefore be our ongoing focus in the future.

\section{REFERENCES}

Bakan, J. 2005. "Das Ende der Konzerne. Die selbstzerstörerische Kraft der Unternehmen“ Hamburg et al.: Europa Verlag.

Banks, J., J. Carson, B. Nelson and D. Nicol. 2005. Discrete-event system simulation, 4th ed. Upper Saddle River, NJ: Pearson Prentice Hall.

Bell, S., Morse, S. 2008. Sustainability Indicators: Measuring the Immeasurable? Sterling, 2nd ed.

Benz, G. 2009. "Naturkatastrophen sind Kulturkatasstrophen! Umwelthistorische Grundlagen von Riosikoanalysen für Naturgefahren“, articlue published in: Beiträge zum Göttinger Umwelthistorischen Kolloquium, Göttingen

Butchart, S.H.M. et al. 2004. "Measuring Global Trends in the Status of Biodiversity: Red List Indices for Birds", PLoS Biol 2(12): e383. doi:10.1371/journal.pbio.0020383, 2004

Butchart, S.H.M. et al. 2007. "Improvements to the Red List Index", PLoS ONE 2(1): e140. doi:10.1371/journal.pone. 0000140

Colantonio, A. 2009. "Social Sustainability", ed. Oxford Institute for Sustainable Development Downloaded under: http://Fec.europa.eu/research/sd/conference/2009/presentations/7/andrea_colantonio__social_sustainability.ppt, (15th May 2011)

Corbera, E., M. Estrada and K. Brown. 2010. "Reducing greenhouse gas emissions from deforestation and forest degradation in developing countries: revisiting the assumptions." Climatic Change, vol. 100, p. 255

Domschke, W. and A. Drexl. 2007. Einführung in Operations Research. 7th edition. Springer, Berlin.

Dubielzig, F. 2009. "Sozio Controlling in Unternehmen, Das Management erfolgsrelevanter sozialgesellschaftlicher Themen in der Praxis“, Gabler Edition Wissenschaft, Dissertation Leuphana Universität Lüneburg, 2008, First edition

FAO (Food and Agriculture Organization of the United Nations). 2007. "The State of world fisheries and aquaculture 2006", Rome

Gasparatos A., M. El-Haram and M. Horner. 2007. "The argument against a reductionist approach for assessing sustainability", International Conference on Whole Life Urban Sustainability and its Assessment M. Horner, C. Hardcastle, A. Price, J. Bebbington (Eds), Glasgow, 2007

Hilty, L.M. and T.F. Ruddy. 2010. "Sustainable Development and ICT interpreted in a natural science context", Information, Communication \& Society, 13: pp. 1, 7-22

Hjorth, P. and A. Bagheri. 2006. "Monitoring for sustainable development: a systemic framework" International Journal of Sustainable Development, Issue: Volume 8, Number 4 / 2005, p. 280-301

Insight Investment 2003. "Labour Standards and Working Conditions in Supply Chains." Downloaded from www.insightinvestment.com/documents/responsibility/ir_labour.pdf (28th Mai 2008)

IPCC (Intergovernmental Panel on Climate Change) 2007. IPCC Assessment Report

Joschko, P., Page, B. and V. Wohlgemuth. 2009. "Combination of Job Oriented Simulation with Ecological Material Flow Analysis as integrated Analysis Tool for Business Production Processes." In Proceedings of the 2009 Winter Simulation Conference, edited by M. D. Rossetti, R. R. Hill, B. Johansson, A. Dunkin and R. G. Ingalls. Piscataway, New Jersey: Institute of Electrical and Electronics Engineers, Inc.

Jahr, P., Schiemann, L., Wohlgemuth V. 2009. "Development of simulation components for material flow simulation of production systems based on the plugin architecture framework EMPINIA." In: Wittmann, J.; Flechsig, M. (Eds.): Simulation in Umwelt- und Geowissenschaften. Shaker Verlag, Aachen, p. $57-69$ 
Leitschuh-Fecht, H. and Bergius, S. 2007. "Stakeholderdialoge können besser werden“, UmweltWirtschaftsForum, 15 (1), 3-6.

Lynam, J. K., Herdt, R. W. 1989. "Sense and sustainability: Sustainability as an objective in international agricultural research", Agricultural Economics, 3 (4), p. 381 - 398

Mallory, M.L., Gaston, A.J. Gilchrist, H.G. Robertson, G.J. Braune, B.M., 2010, "Effects of Climate Change, Altered Sea-Ice Distribution and Seasonal Phenology on Marine Birds", from A Little Less Arctic: Top Predators in the World's Largest Northern Inland Sea, Hudson Bay

Mantow, W. 1995. "Die Ereignisse um Brent Spar in Deutschland: Darstellung und Dokumentation mit Daten und Fakten; Hintergründe und Einflussfaktoren“; Kommentare und Medienresonanzen. Hamburg: Deutsche Shell AG.

McElroy, M. W., Jorna, J. R., van Engelen, J. 2007. "Sustainability Quotients and the Social Footprint" published in Corporate Social Responsibility and Environmental Management, John Wiley and Sons Ltd and The European Research Press Ltd

Meadows et. al. 1972. "The Limits to Growth", Report of the Club of Rome

Möller, A. 2000. "Grundlagen stoffstrombasierter betrieblicher Umweltinformationssysteme“. ProjektVerlag, Bochum.

Murray, S. 2002. "The Supply Chain. Working Lives under Scrutiny." Downloaded under www.theglobalalliance.org/documents/FinancialTimes1202article_000.pdf (20th Mars 2005)

Mintzberg, H. 1983. "The Case for Corporate Social Responsibility", The Journal of Business Strategy, 4 (2), p. 3-15.

Neumayer, E. 2004. Weak versus Strong Sustainability: Exploring the Limits of Two Opposing Paradigms, 2nd ed. Edward Elgar, Cheltenham.

OECD (Organization for Economic Cooperation and Development) 2008. "Measuring material flows and resource productivity", Synthesis Report, Paris

Page, B., Lechler, T., Claassen, S. 2000. "Objektorientierte Simulation in Java mit dem Framework Desmo-J."Libri Books, Hamburg.

Page, B. and Kreutzer, W. 2005. "The Java Simulation Handbook: Simulating Discrete Event System with UML and Java." Shaker Verlag, Aachen.

Pezzey, J. 1992. "Sustainability: An Interdisciplinary Guide.” Environmental Values 1, 1992, p. 321 - 362

Pretty, J. 1995. "Participatory learning for sustainable agriculture", World Development, Vol. 23 No.8, 1995, p.1247-1263, World Development, 8th edition

Rottke, N. B., 2009. "Ökonomie versus Ökologie - Nachhaltigkeit in der Immobilienwirtschaft?“, Köln

Schmidt-Bleek, F. 2008. "Nutzen wir die Erde richtig?: Von der Notwendigkeit einer neuen industriellen Revolution", Frankfurt

SERI 2008, "Global Resource Extraction", taken from the Homepage of the World Resource Forum, under http://www.worldresourcesforum.org/the-issue, 04.06.2011

Sokolowski, J. A., Banks, C. M. 2009. "Principles of Modeling and Simulation.”, Hoboken, NJ: Wiley. p. 6. ISBN 978-0-470-28943-3.

Stahlmann, V. 2008. "Lernziel: Ökonomie der Nachhaltigkeit", München

UN (United Nations) 2001. "Indicators of Sustainable Development: Guidelines and Methodologies." UN Department of Economic and Social Affairs, Division for Sustainable Development. New York.

von Pappenheim, J. R. 2009. "Das Prinzip Verantwortung", Gabler, GWV Fachverlage GmbH

Wöhe, G. and Döring, U. 2008. "Einführung in die Betriebswirtschaftslehre." 23th edition. Vahlen.

Wohlgemuth, V., Bruns, L., Page, B. 2001. "Simulation als Ansatz zur ökologischen und ökonomischen Planungsunterstützung im Kontext betrieblicher Umweltinformationssysteme (BUIS)“, in: Hilty, L.M., Gilgen, P.W. (Hrsg.): Sustainability in the Information Society. 15. Internationales Symposium "Informatik für den Umweltschutz" der Gesellschaft für Informatik (GI), Zürich 2001. Metropolis Verlag, Marburg, Band 2, S. 999-1008.

Wohlgemuth, V., Page, B., Mäusbacher, M., Staudt-Fischbach, P. 2004. "Component-Based Integration of Discrete Event Simulation and Material Flow Analysis for Industrial Environmental Protection: A 
Case Study in Wafer Production.” In Proceedings of the 18th International Conference for Environmental Protection, October 21-23, CERN, Geneva, p. 303-312

Wohlgemuth, V. 2005. "Komponentenbasierte Unterstützung von Methoden der Modellbildung und Simulation im Einsatzkontext des betrieblichen Umweltschutzes." University of Hamburg: Thesis $(\mathrm{PhD})$. Aachen: Shaker.

Wohlgemuth, V., Page, B., Kreutzer, W. 2006. "Combining discrete event simulation and material flow analysis in a component-based approach to industrial environmental protection." Environmental Modelling \& Software: 1607-1617.

Wohlgemuth, V., Schnackenbeck, T., Panic, D., Barling, R.-L. 2008. "Development of an Open Source Software Framework as a Basis for Implementing Plugin-Based Environmental Management Information Systems (EMIS)." In Proceedings of the 22nd Int. Conference Environmental Informatics Informatics for Environmental Protection, Sustainable Development and Risk Management, Sep. 2008

WRF (World Resources Forum) 2008. "Draft Declaration of the World Resources Forum"

\section{AUTHOR BIOGRAPHIES}

ANDI H. WIDOK studied Industrial Environmental Computer Science at the HTW Berlin, University of Applied Sciences. He holds a (M.Sc.) degree in Industrial Environmental Computer Science and works as a research assistant at the HTW Berlin. His research interest are mainly sustainability theory and its appliances in computer simulations, cooperative model building, and sustainable software development for organizations. His email is <a.widok@ htw-berlin.de>.

VOLKER WOHLGEMUTH studied Computer Science at the Universities of Hamburg and Canterbury, Christchurch, New Zealand. He got his PhD in 2005. Since 2005 he is working as a professor for Industrial Environmental Informatics at the HTW Berlin, University of Applied Sciences. His research fields are material flow management, modeling and simulation business systems and Environmental Management Information Systems (EMIS). His email is <volker.wohlgemuth@ @tw-berlin.de>.

BERND PAGE holds degrees in Applied Computer Science from the Technical University of Berlin, Germany, and from Stanford University, USA. As professor for Applied Computer Science at the University of Hamburg he researches and teaches in the field of Computer Simulation as well as in Environmental Informatics. His email is <page@informatik.uni-hamburg.de>. 